\title{
الخصائص السيكومترية لمقياس إدارة الذات لطلاب الثانوية العامة
}

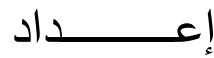

د/ محمد عبد الهادى عبد السميع

أ.د/عبد المنعم أحمد الدردير

قسم علم النفس التربوى

عميد كلية التربية بقتا سابقاً

كلية التربية بقتا

وكيل الكلية لشئون البيئة وخدمة المجتمع

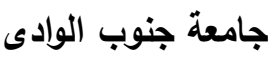

جامعة جنوب الوادى

أ/ إقبال أحمد أبو المجد أحمد

باحثة ماجستير - قسم علم النفس التربوى

كلية التربية بقتا

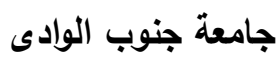




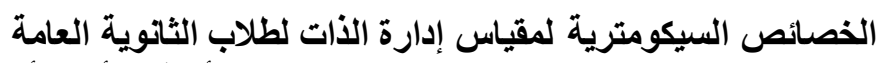

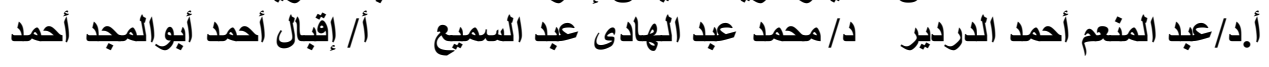

: (المستخلص : n

يجهد البحث الحالى إلى التحقق من الخصائص السيكومترية لمقياس إدارة الذات لطلاب

الثانوية العامة ، وبلغ حجم العينة الاستطلاعية (Y) (Y) طالب وطالبة ، بمتوسط عمر زمنى

(7 (1) عام ، ويبلغ عدد عبارات المقياس (Yo) عبارة ، وقد استخدمت الباحثة أسلوب التحليل

العاملى من الدرجة الأولى مع التدوير المتعامد باستخدام طريقة الفاريمكس ، وأسفرت نتائج التحليل عن ارتباط عبارات المقياس بالدرجة الكلية له بمعاملات ارتباط جميعها دال عند مستوي (0,01)، كما أسفر التحليل العاملي عن استخلاص سبع عوامل يتضمنه المقياس جميع تنبعاتها اكبر من 0,3 ، وأصبحت عبارات المقياس (9 §) عبارة بعد حزف (ه) عبارات ناتج التحليل العاملى .

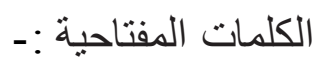
الخصائص السيكومترية ، مقياس إدارة الذات ، طلاب الثانوية العامة . 
الخصائص السيكومترية لمقياس إدارة الذات لطلاب الثاتوية العامة

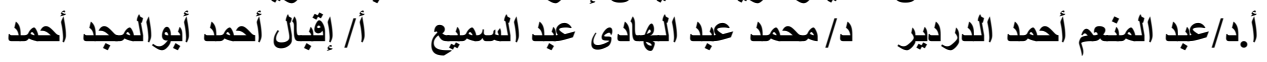

\section{The current research aims to verify the psychometric} properties of a measure of self - management of high school

\section{students}

Prof.Dr.Abd-Elmnem Ahmed El-Drder

Dean of Faculty of Education, Qena

Vice Dean for Environmental Affairs

and Community Service

South Valley University
Dr.Mohamed Abd-Elhady Abs-Elsamea Department of Educational Psychology Faculty of Education

South Valley University

\section{Iqbal Ahmed Abo-Elmagd Ahmed \\ Department of Educational Psychology \\ Faculty of Education \\ South Valley University}

\section{Abstract}

The current research aims to verify the psychometric properties of a measure of self - management of high school students. The size of the survey sample was (211) students, with an average age (17) years. The number of items of the scale (52) Phrases. The Researcher used factor Analysis of the first class with Rotation Orthogonal using Fareemics method. Analysis results indicate the relation of the scale statements with the total result for it at level (0.01). The factor Analysis resulted in the extraction of seven factors that the scale include all their saturation Larger than 0,3, And the items of the scale became(49) after deleting (5) items of the outcome of the factor analysis.

\section{Keywords;}

Psychometric properties - self-management scale - secondary school students . 
الخصائص السيكومترية لمقياس إدارة الذات لطلاب الثاتوية العامة

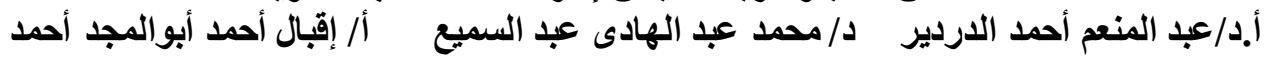

مقدمة : مارة

إدارة الذات : self management

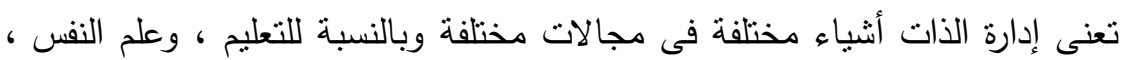

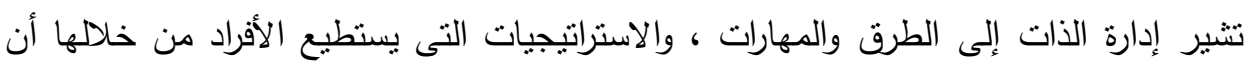

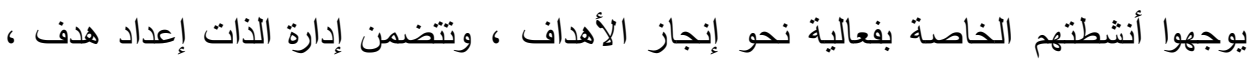

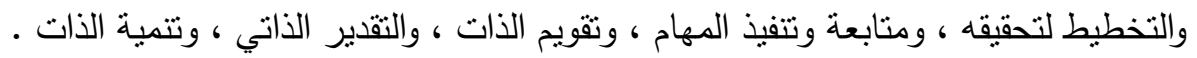

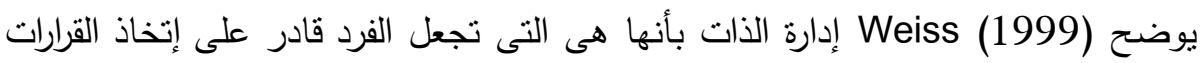

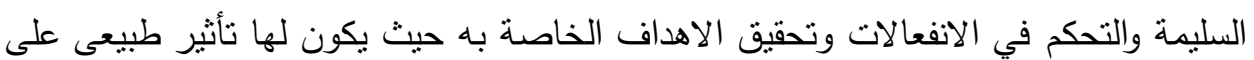

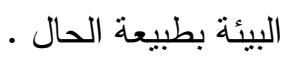

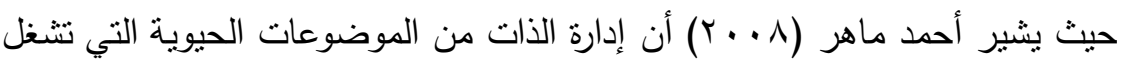

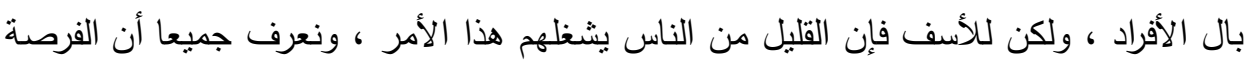

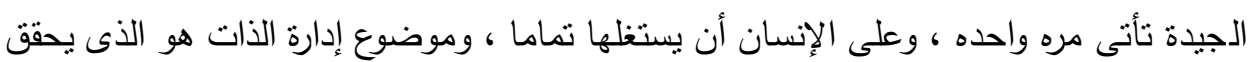

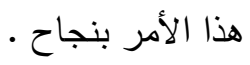

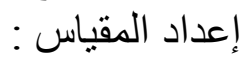
قامت الباحثة ببناء مقياس إدارة الذات لطلاب الصف الثانى الثانوى العام ، على النحو

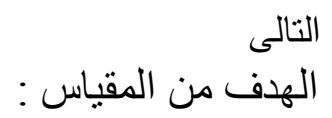

هدف هذا المقياس لقياس إدارة الذات لدى طلاب الثانوية العامة من خلال مجموعة من

$$
\text { الإعتبار ات التىلى روعيث عند إعداد المقياس : }
$$

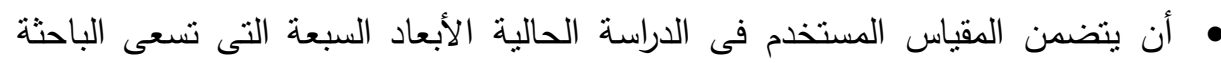

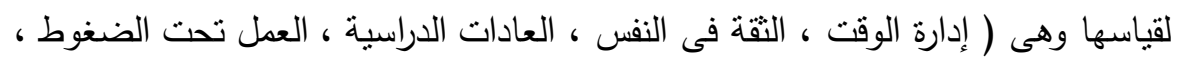

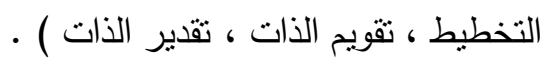
راعت الباحثة عند صياغة المقياس أن تكون العبارات سلسة من الناحية اللغوية ، وأن

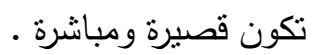
قامت الباحثة بتوضيح الهدف من المقياس لأفراد العينة بشكل مبسط ، مع التأكيد على ألا

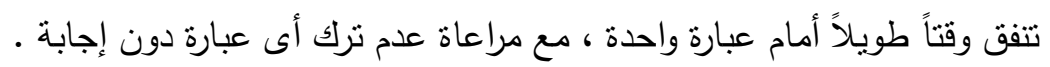

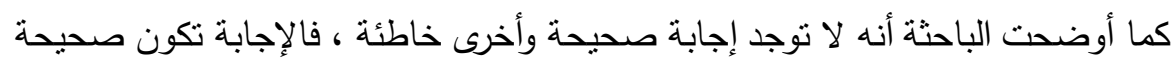

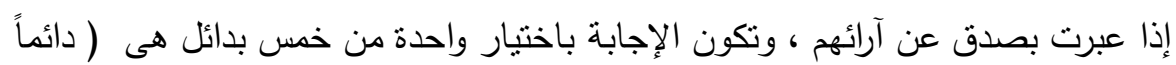

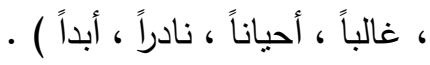


الخصائص السيكومترية لمقياس إدارة الذات لطلاب الثانوية العامة

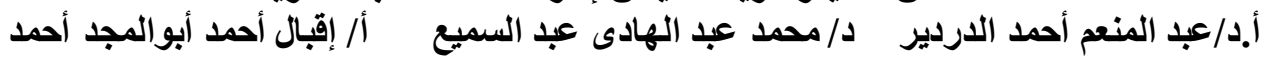

وأيضاً راعت الباحثة عدم ترتيب العبارات بالتسلسل لكى لا يوحى للطالب بطريقة الإجابة

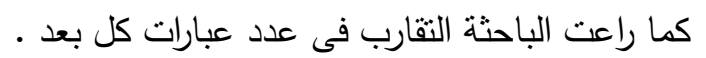

كما راعت الباحثة أن تكون الأبعاد متعددة ومتتوعة كى نشمل المقياس كله .

تصميم المقياس :

قامت الباحثة بالإطلاع على بعض المراجع العربية والأجنبية لتحديد التعريف الإجرائى

ل للأبعاد .

قامت الباحثة بالإطلاع على بعض الدراسات السابقة للإستقادة منها فى تحديد الأبعاد التى تتاسب الدراسة الحالية .

قامت الباحثة بالإطلاع على بعض المقاييس الخاصة بإدارة الذات ومنها على سبيل المثال

\begin{tabular}{|c|c|c|c|c|}
\hline خيار ات الإجابة & العبار ات & العمرية المرية & | الأبعاد & اسم المقياس ولمن نسب \\
\hline أوافق تماماً، أوافق إلى حد ما، & - ج ج عبارة & المرحلة & $\begin{array}{l}0 \\
\text { أبعاد }\end{array}$ & 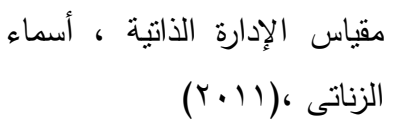 \\
\hline دائماً ، غالباً ، أحياناً ، نادرا ، & r r عبارة & أساتذة & أبعاد & 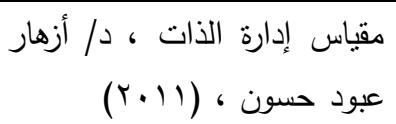 \\
\hline لد دائماً ، غالباً ، أحياناً ، نادراً ، & S ع عبارة & المرحلة الثانوية & أبعاد & مقياس إدارة الذات ، مصطفى \\
\hline أوافق بشدة ، أوافق ، محايد ، & 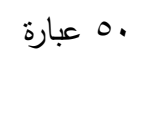 & المرحلة الجامعية & أبعاد & حسن اختبار إدارة الذات ، د د/ناجى \\
\hline صح أو خطأ & · عبارات & 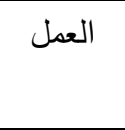 & واحد & تقيم الذات ، wies (1999) \\
\hline صح أو خطأ & • & العمل & واحد & تقدير الذات ، wies (1999) \\
\hline صح أو خطأ & مب عبارة & 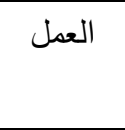 & واحد & 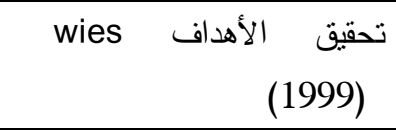 \\
\hline أوافق تماماً ، أوافق أحياناً ، لا & كل 10 موقف موقف أسفل & 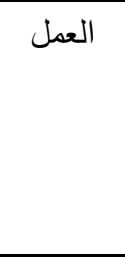 & واحد & التعامل مع المواقف \\
\hline
\end{tabular}


الخصائص السيكومترية لمقياس إدارة الذات لطلاب الثانوية العامة

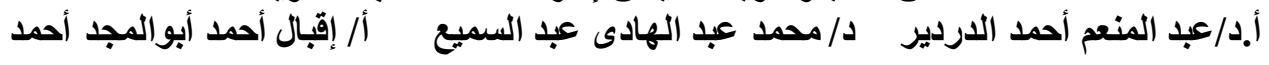

وبناءاً على ما سبق قامت الباحثة بتصميم مقياس إدارة الذات . المفهوم الاجرائى لإدارة الذات : تعرف الباحثة إدارة الذات إجرائياً بأنها مجموعة الإمكانات

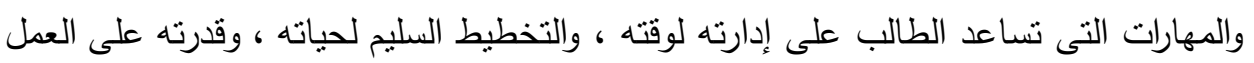
تحت شتى الضغوط ، وتقويمه لذاته عند الخطأ ، واستخدام أفضل الطرق والعادات وأيسرها للإستذكار ، ومدى تقدير الفرد لذاته وتقدير الغير له ، ويعرف مسنوى الطالب في إدارته لذاته واتهاته بالدرجة التى يحصل عليها فى الأبعاد الفرعية المكونة للمقياس وهى ولفي (التخطيط-العادات

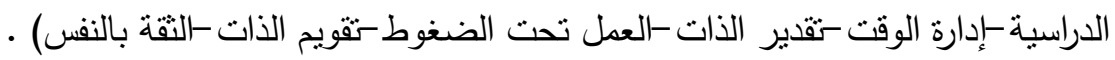

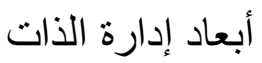

1 ا ـالتخطيط : وتعرفه الباحثة إجرائياً فى البحث الحالى بأنه قدرة الطالب على وضع تصور مبلئى

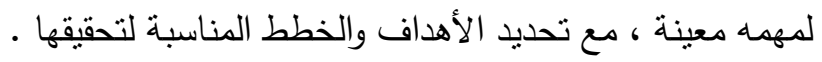

$$
\text { وعباراته هى : }
$$

لا أجد هدف لتحقيقه

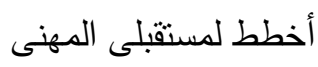

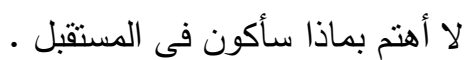

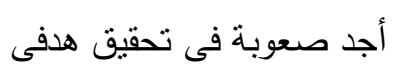

دائماً هناك عقبات فى طريقى للنجاح

يطلب الآخرون منى خفض صوتى أثناء المناقثنة .

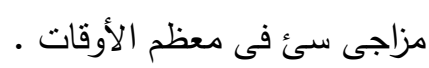

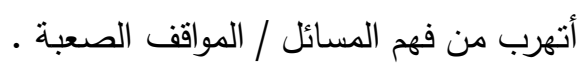

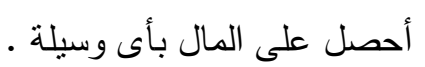

r ـ العادات الدراسية : وتعرفها الباحثة إجرائياً فى البحث الحالى بأنها قدرة الطالب على معرفة أفضل طريقة لإستذكاره لدروسه التى تساعده على تحقيق النجاح والتميز . وعباراته هى : -

أستطيع معرفة أخطائى والقدرة على تصحيحها .

اقضى وقت كبير فى مشاهدة التلفزيون / الإنترنت .

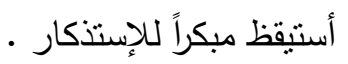

أنرك المذاكرة لسماع فيلم /مباراة كرة قدم.

أثنعر بتقدير أسرتى لى . 
الخصائص السيكومترية لمقياس إدارة الذات لطلاب الثانوية العامة

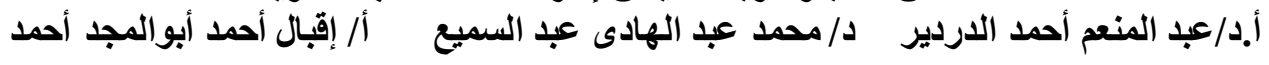

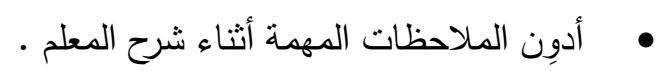

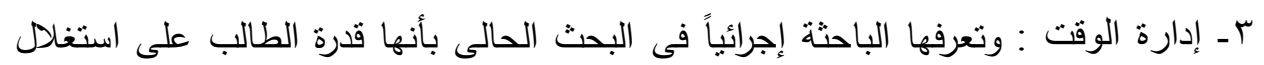

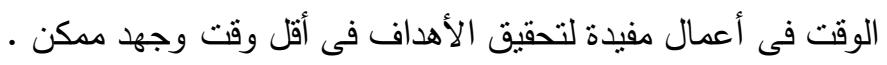

$$
\text { وعباراته هى : - }
$$

ألتزم بتتفيذ جدول أعمالى فى موعده . بصعب عليا نتظيم أوقانى

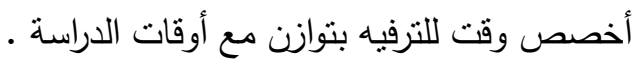

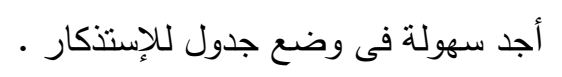

لاى قدرة تحديد الوقت الذى تستغرقه مهمه معينه .

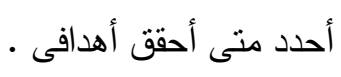

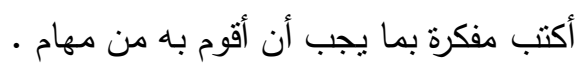

من الصعب استثارتى إنفعالياً .

ع ـتقويم الذات : وتعرفه الباحثة إجرائياً فى البحث الحالى بأنه معرفة الطالب لحقيقة سلوكه ،

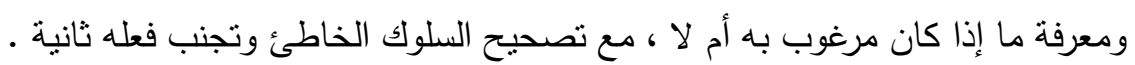

$$
\text { وعباراته هى :- }
$$

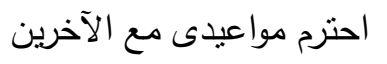

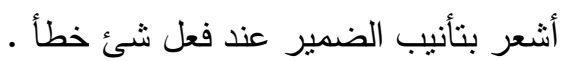

أكرر السلوك الملائم واتجنب السلوك الخطأ .

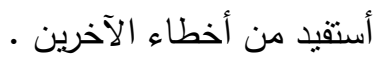

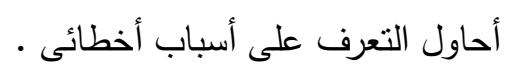

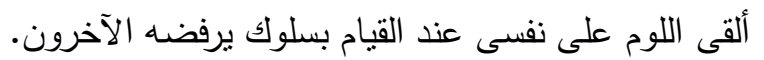

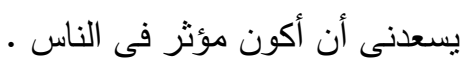

أحاول أن أنغير عندما أعرف أننى أقوم بأنشياء خاطئة .

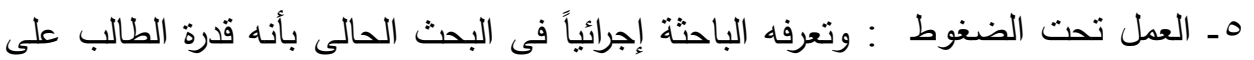

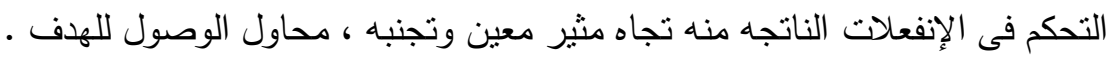

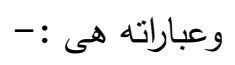

أهدئ من انفعالاتى الناتجة عن أى مشكلة تواجنى . أنسى

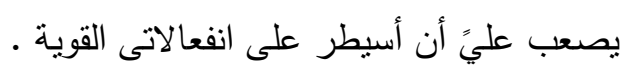


الخصائص السيكومترية لمقياس إدارة الذات لطلاب الثانوية العامة الثادية

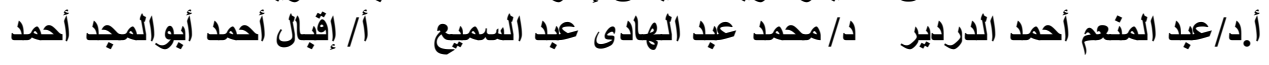

• أتثتع بالصبر فى جميع المواقف .

أشعر بالتقصير من الناحية الدينية .

أشعر بالرضى عن نفسى دائماً .

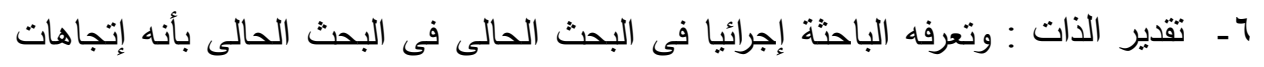

الطالب نحو نفسه وتكون شاملة الإتجاهات الإيجابية والإتجاهات السلبية .

وعباراته هى : -

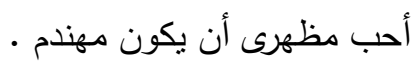

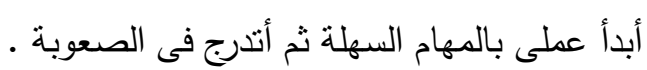

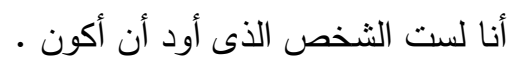

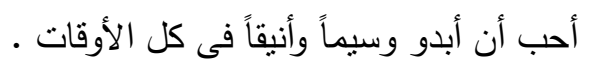

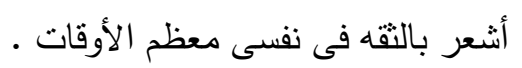

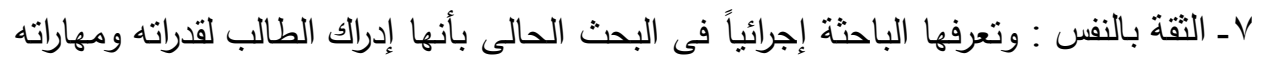

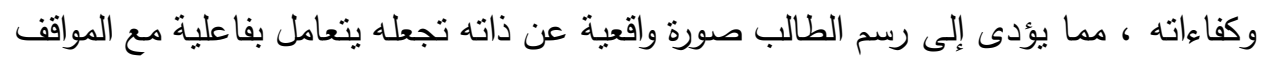

$$
\text { والأحداث . واكاءه ، معاته }
$$$$
\text { وعباراته هى :- }
$$

يقلقنى التواجد مع عدد كبير من الناس •

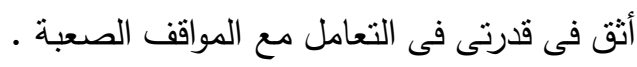

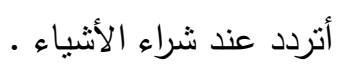

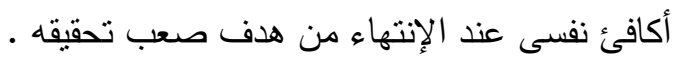

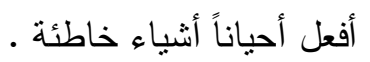

صدق المقياس

استخدمت الباحثة أسلوب التحليل العاملى من الدرجة الأولى مع التدوير المتعامد

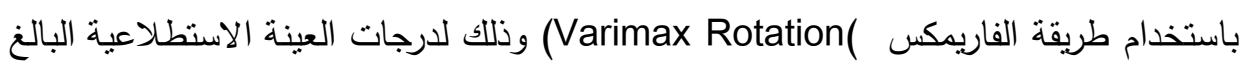

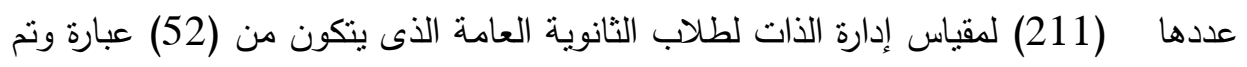
إجراء التحليل العاملي Factorial Analysis لبنود المقياس، وتم تحلبلها عاملياً بطريقة

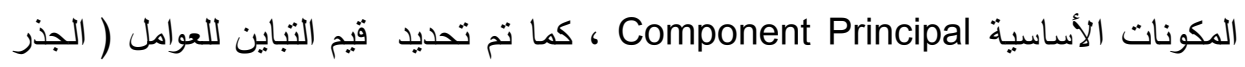
الكامن) ركما تم إجراء التدوير بطريقة بروماكس Rotation Promax للعوامل . واتبعت الباحثة المحكات الآتية : - 
الخصائص السيكومترية لمقياس إدارة الذات لطلاب الثاتوية العامة الثادية

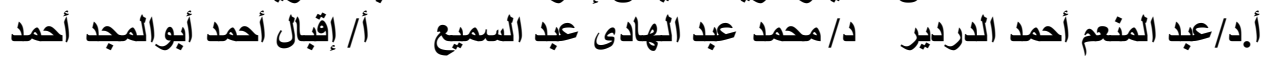

تم أخذ العوامل التى جذرها الكامن أكبر من أو يساوى الواحد الصحيح •

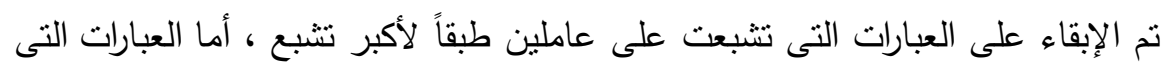

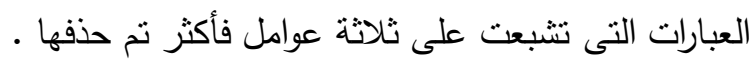

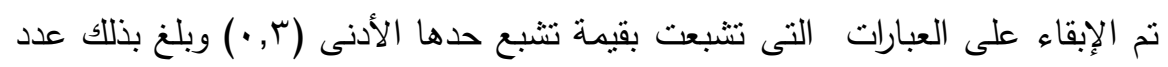

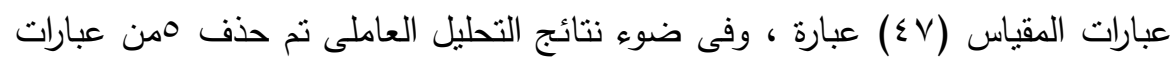

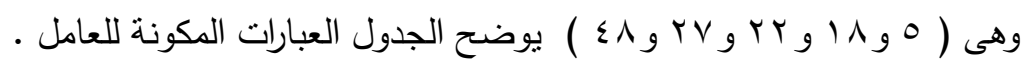

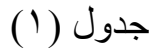

الجذور الكامنة والنسب المئوية لتباين عوامل مقياس إدارة الذات لطلاب الثانوية العامة

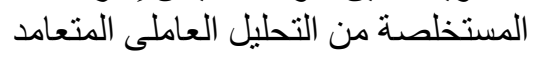

\begin{tabular}{|c|c|c|c|}
\hline النسب المئوية لتباين العوامل & الجذر الكامن & ترتيب العامل & 5 \\
\hline T. $\leqslant V Y$ & ת. & التخطيط & 1 \\
\hline 7.ะรT & r. & العادات الدراسية & r \\
\hline 7.410 & r.trt & إدارة الوقت & r \\
\hline $0 . V Y q$ & r. $9 \vee 9$ & تقويم الذات & $\varepsilon$ \\
\hline$\varepsilon . \vee 00$ & r. $\Sigma V T$ & العمل تحت الضغوط & 0 \\
\hline$\varepsilon . \vee 0$. & T. $\Sigma V$. & تقدير الذات & 7 \\
\hline r.А. & $1.9 \times 9$ & الثقة بالنفس & v \\
\hline
\end{tabular}

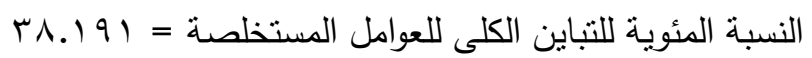

جدول (1)

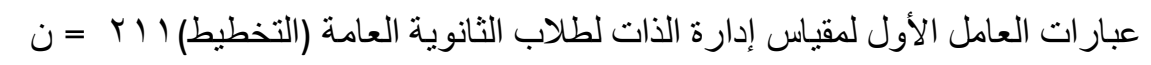

\begin{tabular}{|c|c|c|c|c|c|}
\hline التشبع & 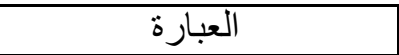 & 5 & التشبع & 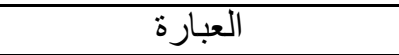 & 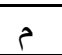 \\
\hline 0.330 & بطلب الآخرون منى خفض أثناء المناقشة & 39 & 0.457 & دائماً هناك عقبات فى طريقى & 1. \\
\hline 0.546 & أخطط لمستقبلى المهنى. & 41 & 0.368 & مزاجى سىء فى معظم الأوقات & 10 \\
\hline 0.703 & لا أجد هدف لتحقيقه. & 46 & 0.457 & أجد صعوبة فى تحقيق هدفى . & 17 \\
\hline 0.370 & أحصل على المال بأى وسيلة. & 52 & 0.637 & لا أهتم بماذا سأكون فالمستقبل & ro \\
\hline & & & 0.468 & أنهرب من فهم المسائل / الصعبة . & Tr \\
\hline
\end{tabular}


الخصائص السيكومترية لمقياس إدارة الذات لطلاب الثانوية العامة

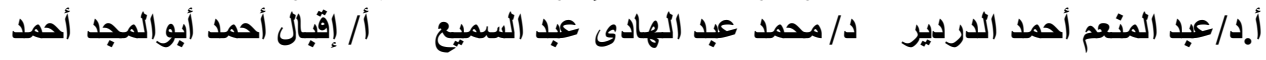

يتضح من استعراض جدول ( 1 ) أن العامل الأول تشبعت به ( 9 ) عبارات

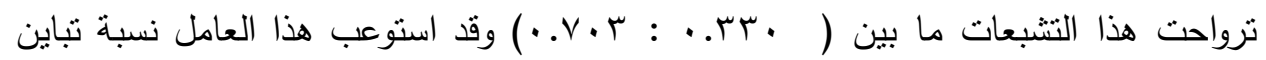

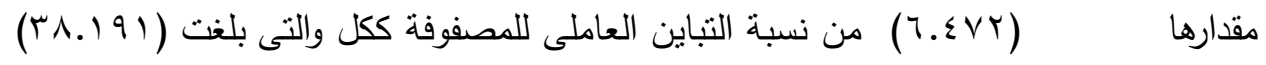

حيث ان عبارات هذا العامل تدور حول قدرة الفرد على التخطيط لذلك سمى العامل ( التخطيط )

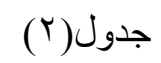

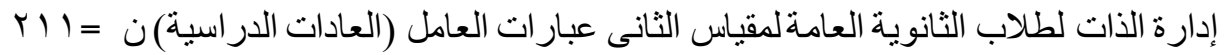

\begin{tabular}{|c|c|c|c|c|c|}
\hline التشبع & العبارة & r & التشبع & العبارة & 5 \\
\hline 0.439 & أشعر بتقدير أسرتى لى. & 36 & 0.492 & 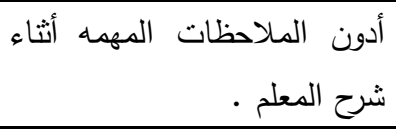 & $r$ \\
\hline 0.383 & على تصنيع معرفة أخطائى والقدرة & 42 & 0.615 & 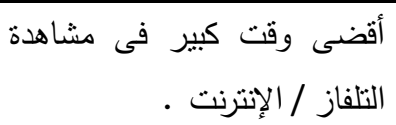 & $r$. \\
\hline 0.616 & أترك المذاكرة لسماع فيلم / & 44 & 0.411 & أستيقظ مبكراً للإستذكار . & r \\
\hline & & & 0.578 & أرعمل عناء اليوم لكى أحقق ما & ו ו \\
\hline
\end{tabular}

يتضح من استعراض جدول ( r ) أن العامل الثانى تشبعت به ( V ) عبارات

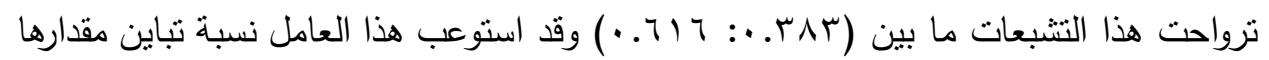

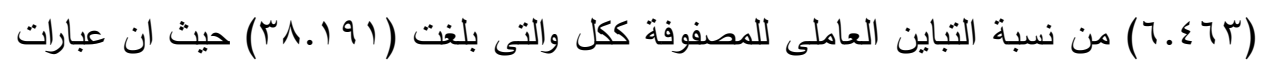
هذا العامل تدور حول العادات الدراسية التى يقوم بها الطلاب لذلك سمى العامل ( العادات • (الدراسية)

جدول(r) (بان)

إدارة الذات لطلاب الثانوية العامة لمقياس الثالث عبار ات العامل (إدارة الوقت )

Y) $=\dot{0}$

\begin{tabular}{|c|c|c|c|c|c|}
\hline التشبع & العبارة & م & 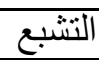 & العبارة & م \\
\hline 0.599 & للجإستذكار. سهولة فى وضع جدول & 30 & 0.478 & تلدتى قدرة تحديد الوقت الذى مهينه & 1 \\
\hline 0.420 & يصعب عليا نتظيم أوقاتى & 38 & 0.482 & 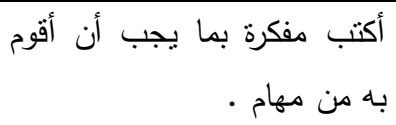 & $r$ \\
\hline
\end{tabular}




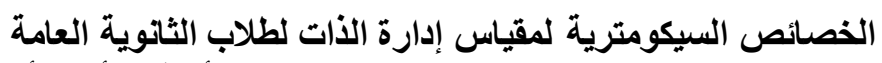

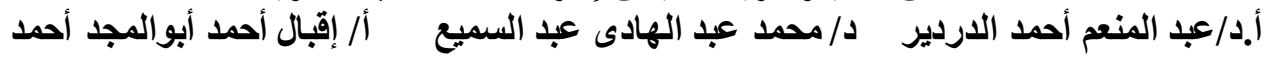

\begin{tabular}{|c|c|c|c|c|c|}
\hline التشبع & العبارة & r & التشبع & العبارة & م \\
\hline 0.420 & أحدد متى أحقق أهدافى. & 47 & 0.384 & من الصعب استثارتى إنفعالياً & $r \wedge$ \\
\hline 0.537 & ألتزم بتتفيذ جدول أعمالى فى & 50 & 0.400 & أخصص وقت للترفيه بتوازن مع & rq \\
\hline
\end{tabular}

يتضح من استعراض جدول ( r ) أن العامل الثالث نشبعت به ( ^) عبارات

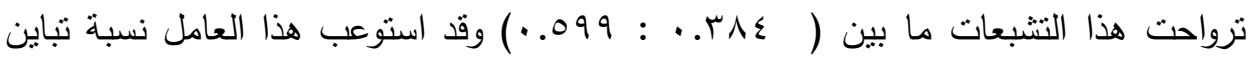

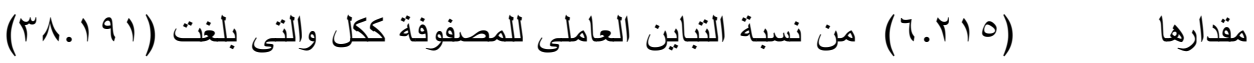

حيث ان عبارات هذا العامل تدور حول قدرة الفرد على إدارة وقته لذلك سمى العامل ( إدارة

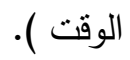

جدول(

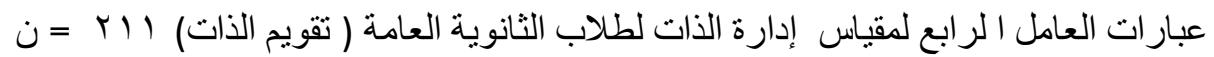

\begin{tabular}{|c|c|c|c|c|c|}
\hline التشبع & العبارة & م & التشبع & العبارة & r \\
\hline 0.529 & 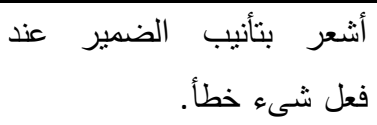 & 34 & 0.551 & أحاول أن أنغير عندما أعرف أقوم بأثنياء خاطئة . & $\varepsilon$ \\
\hline 0.351 & أكرر السلوك الملائم واتجنب & 35 & 0.401 & أحترم مواعيدى مع الآخرين . & $\wedge$ \\
\hline 0.589 & يسعنى أن أكون مؤثر فالناس & 43 & 0.582 & أخطاول التعرف على أسباب & 9 \\
\hline 0.583 & ألقى اللوم على نفسى عند & 45 & 0.572 & أستفيد من أخطاء الآخرين . & r) \\
\hline
\end{tabular}

يتضح من استعراض جدول ( ع ) أن العامل الرابع نشبعت بـ ( ^) عبارات ترواحت

هذا التشبعات ما بين (101. (

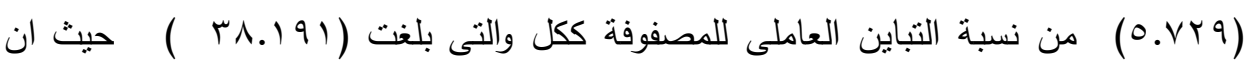
عبارات هذا العامل تدور حول قدرة الفرد على تقويم ذاته لذلك سمى العامل ( تقويم الذات ) . (0) (0) 
الخصائص السيكومترية لمقياس إدارة الذات لطلاب الثاتوية العامة

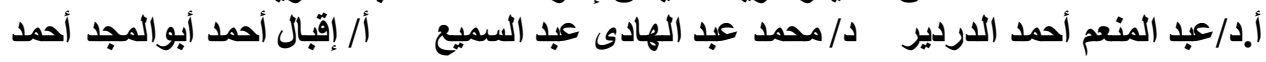

) العمل تحت الضغوط ( إدارة الذات لطلاب الثانوية العامة لمقياس الخامس عبار ات العامل ن (1) =

\begin{tabular}{|c|c|c|c|c|c|}
\hline التشبع & العبارة & م & التشبع & العبارة & م \\
\hline $.7 T V$ & 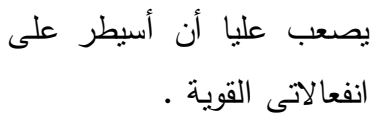 & 19 & 0.622 & 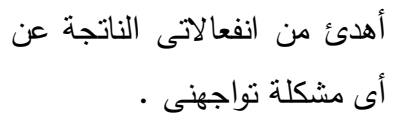 & V \\
\hline 0.615 & أتنتع بالصبر في جميع & 49 & 0.634 & أشنعر بالرضى عن نفسى دائماً & 11 \\
\hline & & & 0.353 & 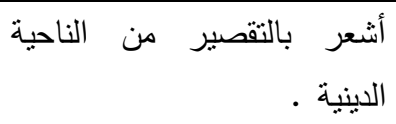 & $1 \pi$ \\
\hline
\end{tabular}

يتضح من استعراض جدول (0) أن العامل الخامس نشبعت به (0) عبارات نرواحت

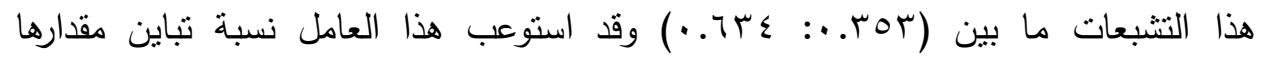

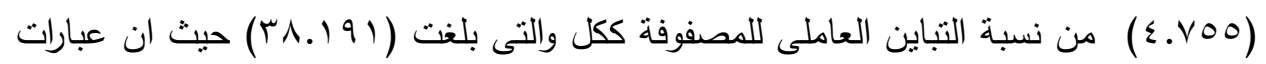
هذا العامل تدور حول قدرة الفرد على العمل تحت الضغوط لذلك سمى العامل ( العمل تحت (الضنوط)

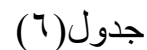

تقدير الذات) (إدارة الذات لطلاب الثانوية العامة لمقياس السادس عبار ات العامل

Y) $=\dot{0}$

\begin{tabular}{|c|c|c|c|c|c|}
\hline التشبع & العبارة & 5 & التشبع & العبارة & 5 \\
\hline 0.949 & 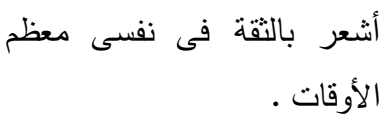 & 40 & 0.393 & 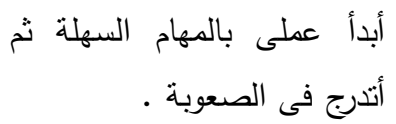 & $T \varepsilon$ \\
\hline \multirow[t]{2}{*}{0.737} & أحب مظهرى أن يكون مهندم & 51 & 0.373 & أنا لست الشخص الذى أود أن & ru \\
\hline & & & 0.760 & 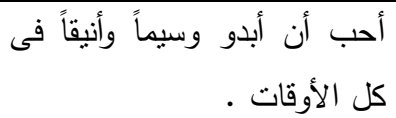 & rr \\
\hline
\end{tabular}

يتضح من استعراض جدول (T) أن العامل الساد تشبعت به ( 0) عبارات ترواحت

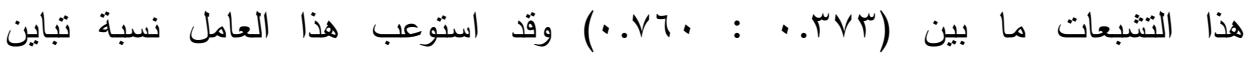

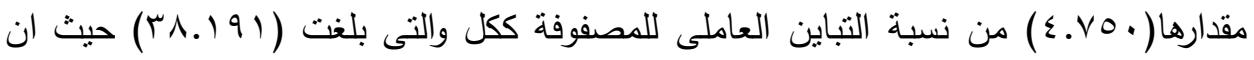
عبارات هذا العامل تدور حول تقدير الفرد لذاته لذلك سمى العامل ( تقدير الذات ) . (v) جدول 
الخصائص السيكومترية لمقياس إدارة الذات لطلاب الثاتوية العامة

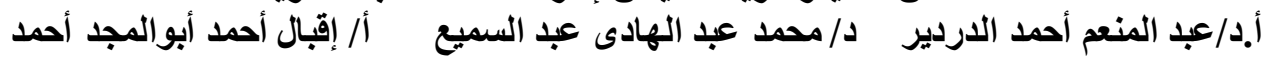

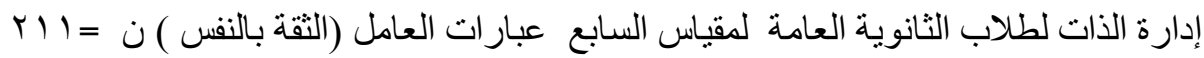

\begin{tabular}{|c|c|c|c|c|c|}
\hline التشبع & العبارة & 5 & التشبع & العبارة & 5 \\
\hline 0.338 & 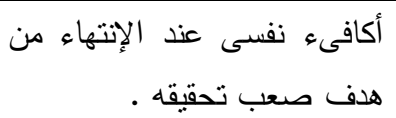 & IV & 0.620 & أتردد عند شراء الأشياء . & 7 \\
\hline \multirow[t]{2}{*}{0.333} & يقلقى التواجد مع عدد كبير من & 37 & 0.514 & أفعل أحياناً أثنياء خاطئة & ir \\
\hline & & & 0.427 & ألثق فى قدرتى فى التعامل مع & $1 \varepsilon$ \\
\hline
\end{tabular}

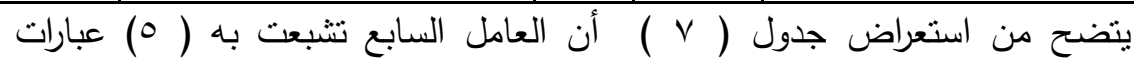

ترواحت هذا التشبعات ما بين (Trس. • : • ج T. • ) وقد استوعب هذا العامل نسبة تباين مقدارها

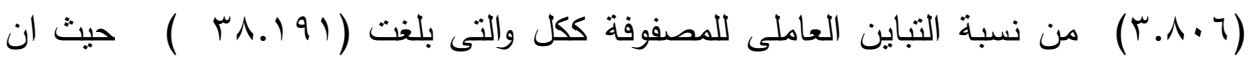
عبارات هذا العامل تدور حول مدى ثقة الفرد بنفسه لذلك سمى العامل ( التقة بالنفس) .

ثبات المقباس : ت

قامت الباحثة أيضا بحساب ثبات المقياس باستخدام معامل ألفا كرونباخ، وقد تراوحت قيمة ألفا (آحـ. •و • •و. • ) وهو معامل دال إحصائيا يدل على إن مقياس ادارة الذات قيد

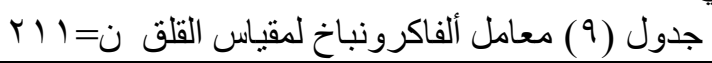

\begin{tabular}{|c|c|c|c|}
\hline بعد تطبيق معادلة التصحيح معامل ألفا & معامل & البعد & r \\
\hline 0.811 & 0.683 & التخطيط & 1 \\
\hline 0.829 & 0.708 & العادات الدراسية & r \\
\hline 0.807 & 0.677 & إدارة الوقت & $r$ \\
\hline 0.807 & 0.677 & تقويم الذات & $\varepsilon$ \\
\hline 0.787 & 0.649 & العمل تحت الضغوط & 0 \\
\hline 0,746 & 0,595 & تقدير الذات & 7 \\
\hline 0,461 & 0,300 & الثقة بالنفس & $\checkmark$ \\
\hline 0,921 & 0,825 & الدرجة الكلية & $\wedge$ \\
\hline
\end{tabular}

المقياس :

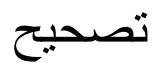




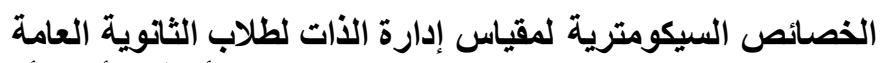

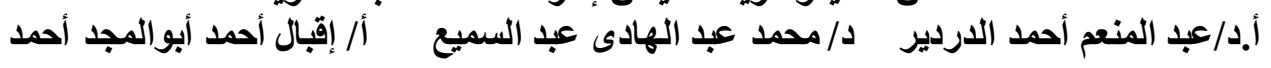

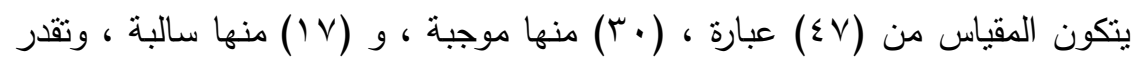

الدرجات فى حالة العبارات الموجبة كما يلى :

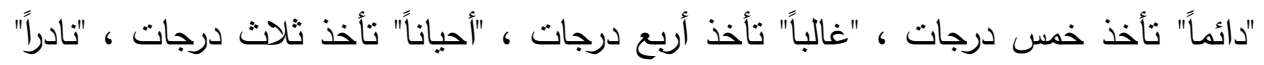

$$
\text { تأخذ درجنين ، "أبداً" تأخذ درجة واحدة . }
$$

والعبارات

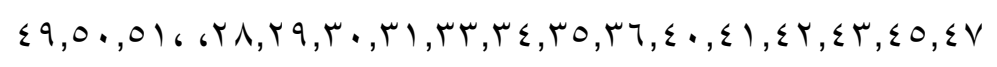

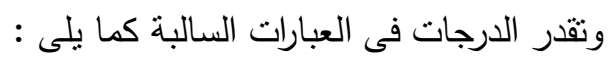

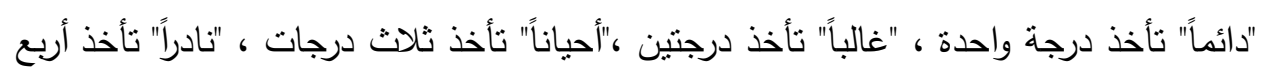

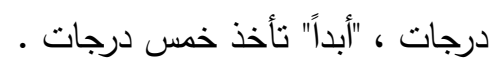

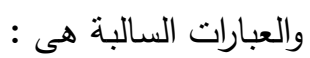

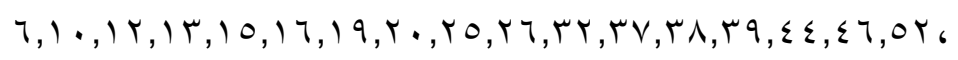




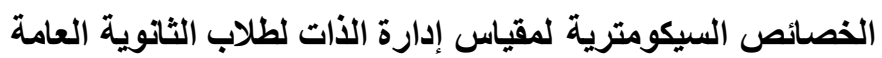

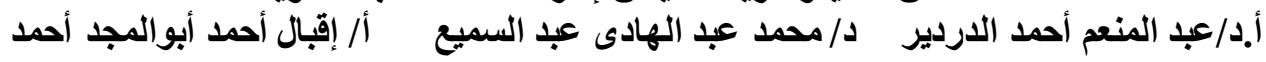

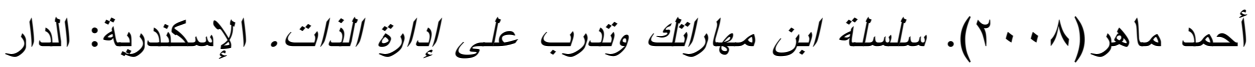

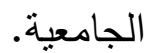

أزهار عبود حسون (11 (1). بناء مقياس إدارة الذات وفقاً لنظرية كولمان لدى تدريسى

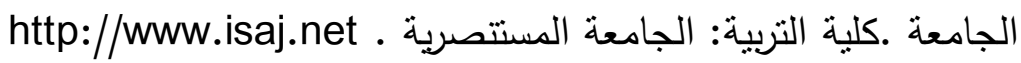

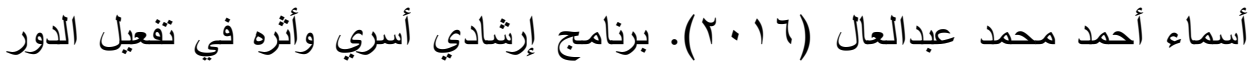

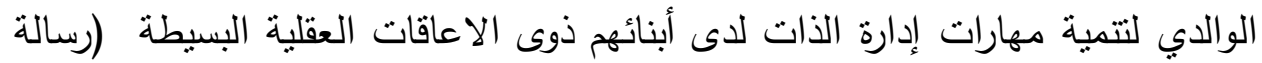
دكتوراه) .كلية التربية : جامعة عين شمس.

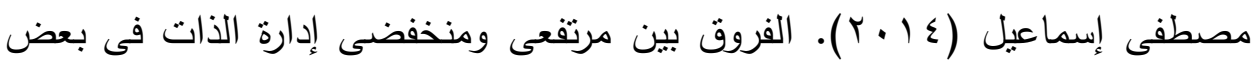

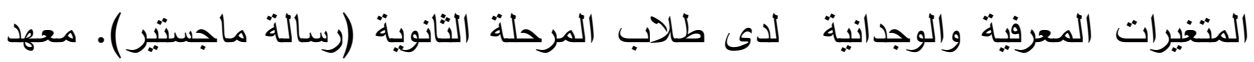
الدراسات التربوية: جامعة القاهرة . ناجي محمد حسن (د.ت). اختبار إدارة الذات .كلية التربية: جامعة أسيوط. American Psychological Association(2010).Publication manual of the American Psychological Association $\left(6^{\text {th }} \text { ed. }\right)^{1}$. Washington, DC: Author.

Weiss, D.H.(1999). The self-management workshop: Helping people take control of their lives and their work:Atrainer's guide trainer's workshop series,U.S.A.:AMAKOM Books. 